\title{
Junctional Escape Complexes by ECG Finding
}

National Cancer Institute

\section{Source}

National Cancer Institute. Junctional Escape Complexes by ECG Finding. NCI Thesaurus.

Code C116129.

An electrocardiographic finding of an escape beat following a pause that originates at the AV junction; this manifests as a QRS complex of supraventricular origin not immediately preceded by a P wave. (CDISC) 